\title{
SYNTHESE PROTÉIQUE IN VIVO DANS DIVERS TISSUS DU RAT EN CROISSANCE EN FONCTION DU RYTHME ALIMENTAIRE
}

\author{
Christiane OBLED, M. ARNAL et G. FAUCONNEAU \\ Laboratoire d'Étude du Métabolisme azoté, \\ Centre de Recherches zootechniques et vétérinaires, I. N.R. A., \\ Theix, 63110 Beaumont
}

\section{RÉSUMÉ}

Des rats à croissance rapide $(6,7 \mathrm{~g} / \mathrm{j})$, éclairés de 7 à $\mathrm{I} 9 \mathrm{~h}$ et nourris, soit ad libitum, soit en 6 repas égaux distribués toutes les 4 heures à partir de ro $\mathrm{h} 30$, reçoivent Io $\mu \mathrm{Ci}$ de $\mathrm{L}-1$ ysine-14 $\mathrm{C}$ par injection intrapéritonéale, soit à $I_{5} \mathrm{~h}$ soit à $23 \mathrm{~h}$. La synthèse protéique dans le foie, l'appareil digestif et différentes fractions protéiques du muscle est estimée par la mesure de la radioactivité incorporée dans les protéines en tenant compte de la radioactivité du précurseur. Le catabolisme protéique dans le foie et le muscle est estimé par la mesure de l'activité catheptasique (D) totale des tissus. Le catabolisme oxydatif de la lysine est déterminé par la mesure de l'évolution de la RAS du ${ }^{14} \mathrm{CO}_{2}$ après l'injection.

Quel que soit le rythme alimentaire des animaux, la quantité de protéines synthétisées par le foie et l'appareil digestif est plus élevée la nuit que le jour. La synthèse protéique dans le muscle semble indépendante du rythme alimentaire puisque les protéines totales et les protéines myofibrillaires sont synthétisées en plus grande quantité durant la phase claire. Cependant, les protéines sarcoplasmiques suivent un rythme parallèle à celui des protéines du foie et de l'appareil digestif.

L'alimentation contrôlée entraîne une réduction des synthèses protéiques dans le foie et l'appareil digestif. Parallèlement, la quantité de lysine oxydée est diminuée. La synthèse protéique réelle du muscle est peu sensible au rythme alimentaire. Cependant la synthèse des protéines sarcoplasmiques est accrue chez les animaux soumis aux repas. Le catabolisme protéique du foie et surtout du muscle est réduit. Cet ensemble de faits est en faveur d'une meilleure rétention azotée de ces animaux.

\section{IN'TRODUCTION}

Le métabolisme de l'animal est susceptible de s'adapter aux variations du milieu externe et en particulier à l'alternance des périodes de jeune et des périodes d'alimentation au cours de la journée. D'après MunRo (rg69), ces adaptations à court terme interviennent pour une large part dans les variations nycthémèrales 
qui ont été observées dans le métabolisme protéique des mammifères et en particulier du rat (WuRTMAN, I970). En effet, l'activité de certaines enzymes hépatiques (FUlLER et SNODY, I967 ; GIRARD-GLOBA et BOURDEL, 1973) et la synthèse protéique dans le foie, évaluée soit par la détermination du profil polyribosomique (FIsHMAN et al., r969) soit par l'incorporation d'un acide aminé marqué dans les protéines totales ( $\mathrm{L}_{\mathrm{E}}$ Bouton et HANDL,ER, I970) sont plus importantes la nuit que le jour.

La modification du rythme alimentaire normal a permis de montrer l'influence très importante de la chronologie de l'apport des protéines alimentaires dans la détermination de ces cycles journaliers (GIRARD-Groba et Bourdei, I973). L'influence du rythme alimentaire sur le métabolisme protéique, bien connue dans le foie, l'est beaucoup moins dans d'autres tissus, le muscle en particulier.

La relation entre la rétention azotée et la fréquence des repas a été étudiée par de nombreux auteurs (CoHN et JosEPH, I959; FABRY, I967; FRIEND, I967).

Une étude réalisée au laboratoire à l'aide de bilans, a montré que la distribution de la ration en 6 repas égaux, régulièrement espacés au cours de la journée, permet d'obtenir un gain d'azote significativement plus élevé (5 p. Ioo) que la distribution ad libitum (Bouvier et al., 1973). Le but de la présente étude est de déterminer l'influence de l'alimentation contrôlée sur la quantité de protéines synthétisées au cours de la journée dans divers tissus du rat en croissance, en particulier dans le tissu musculaire, et de préciser si l'augmentation de synthèse protéique apparente est le résultat d'une augmentation de l'anabolisme ou d'une diminution du catabolisme protéique ou des deux phénomènes à la fois.

L'anabolisme protéique est déterminé par la mesure de la vitesse d'incorporation de la $\mathrm{L}_{-}-1 y \operatorname{sine} \mathrm{e}^{1{ }^{14} \mathrm{C}}$ dans les protéines. L'intensité du catabolisme protéique est apprécié par la mesure de l'activité catheptasique D totale des tissus. Ce travail a fait l'objet de deux notes préliminaires (OBL,ED et al., I972, I973).

\section{MATÉRIEL E'T MÉTHODES}

\section{I. --. Matériel animal}

A un poids moyen de 70 g. environ, des rats mâles de souche Wistar C. F. sont placés dans une pièce maintenue à température constante $\left(2 \mathrm{I}-22^{\circ} \mathrm{C}\right)$, à un degré hygrométrique contrôlé (60 p. I0o) et éclairée pendant $\mathrm{I} 2$ heures (de $7 \mathrm{~h}$ à $19 \mathrm{~h}$ ). Les animaux reçoivent jusqu'au poids de I I0-I20 g, l'aliment "Sanders " pour rats $(\mathrm{N} \times 6,25=$ I 8 p. Ioo).

A partir de ce poids, ils sont séparés en deux lots homogènes et sont nourris jusqu'à l'abattage avec un régime à base de farine de poisson de Norvège, supplémentée en méthionine, contenant I4 p. Ioo de matières azotées $(\mathrm{N} \times 6,25)$ par rapport à la matière sèche (ARNAL et al., I97I). Les animaux du lot témoin sont nourris ad libitum. Les animaux du lot "repas", après une période d'adaptation de 3 à 4 jours, consomment spontanément en $5 \mathrm{mn}$ environ, chacun des 6 repas égaux distribués toutes les 4 heures à partir de ro h $3^{\circ}$.

\section{2. — Méthodes expérimentales}

$\mathrm{Au}$ poids de $200 \mathrm{~g}$, les rats de chaque lot reçoivent une injection intrapéritonéale de ro $\mu \mathrm{Ci}$ de L-lysine- ${ }^{14} \mathrm{C}$ (U) (activité spécifique $255 \mathrm{mCi} / \mathrm{mM}$ ) soit à $\mathrm{I} 5 \mathrm{~h}$ (groupe jour), soit à $23 \mathrm{~h}$ (groupe nuit).

Les animaux sont ensuite sacrifiés, à raison de 6 animaux par point expérimental, aux temps I $5 \mathrm{mn}, 30 \mathrm{mn}, 60 \mathrm{mn}$ et $120 \mathrm{mn}$ après l'injection.

Dix animaux de chaque lot sont utilisés pour la mesure du catabolisme oxydatif de la lysine. 


\section{3. - Abbattage et prélèvements}

Dix minutes avant l'abattage, l'animal est anesthésié au Nembutal. Le sang est prélevé par ponction intracardiaque, placé dans un tube hépariné et centrifugé à $+4^{\circ \mathrm{C}} 5 \mathrm{mn}$ à 3 ooo $g$. Une partie du plasma est conservée, en vue de sélectionner les animaux (voir paragraphe 4), le reste est conservé à $-20^{\circ} \mathrm{C}$.

La cavité abdominale est ouverte; le contenu frais de l'estomac, pesé, est mis à l'étuve $\left(80^{\circ} \mathrm{C}\right)$ de façon à suivre la vidange stomacale des animaux. Le tube digestif, du cardia au rectum, est lavé par une solution d'acide trichloracétique à Io p. Ioo froid.

Les mésentères, le pancréas et la rate sont rincés dans du sérum physiologique froid, de façon à éliminer le marqueur non absorbé. Le tube digestif, les mésentères, le pancréas et la rate sont réunis pour former le compartiment " appareil digestif ", congelés dans l'azote liquide et conservés à - $20^{\circ} \mathrm{C}$.

Le foie est morcelé et lavé dans du sérum physiologique froid $\left(+t^{\circ} \mathrm{C}\right)$ de façon à éliminer le maximum de sang. Il est séché sur papier filtre, pesé, congelé dans l'azote liquide et conservé à $-20^{\circ} \mathrm{C}$.

Les muscles des membres postérieurs sont disséqués et hachés finement de façon à former un échantillon homogène. La masse musculaire est séparée en 4 fractions dont une seulement est congelée dons l'azote liquide. Deux autres fractions sont placées à - $20^{\circ} \mathrm{C}$ sans congélation préalable. La quatrième fraction (environ $2 \mathrm{~g}$ ) est placée dans $50 \mathrm{ml}$ d'une solution tamponnée (acétate o, I $\mathrm{N}$ Tris $\mathrm{HCl}$ pH 7,2, Triton X-I Oo o,2 p.IOO) en vue de la détermination de l'activité catheptasique D totale. De même, un prélèvement de I $g$ de foie est placé dans la solution tamponnée.

\section{4. - Sélection des animaux}

A l'abattage de chaque animal, $500 \mathrm{mg}$ de plasma sont déféqués par o, $5 \mathrm{ml}$ d'ATC Io p. Ioo. La radioactivité acido-soluble est mesurée et les valeurs obtenues, exprimées en d.p.m./g plasma, sont corrigées pour une même dose injectée de ro $\mu \mathrm{Ci}$.

Pour chaque point expérimental, la valeur moyenne de la radioactivité des composés libres plasmatiques est calculée. Seuls les animaux pour lesquels la valeur de l'écart par rapport à la. moyenne de la radioactivité acido-soluble plasmatique est inférieure ou égale à Io p. roo sont conservés, soit 3 à 6 animaux par point expérimental (OBLED, 1973).

\section{5. - Méthodes analytiques}

Les traitements des divers échantillons visent à séparer la fraction $\mathrm{L}-\mathrm{ly}$ sine-14 $\mathrm{C}$ libre de celle où cet acide aminé se trouve incorporé dans les protéines.

a) Extraction des acides aminés libres.

L'agent d'extraction est l'acide trichloracétique à ıo p. Ioo (ATC Io p. Ioo). La technique utilisée a été décrite par Arnal et al. (1971). Dans le cas du muscle non congelé à l'azote liquide, les acides aminés sont extraits avec les protéines sarcoplasmiques (voir paragr. $5 b$ ). Ils sont séparés des protéines par défécation par un volume d'ATC Io p. roo (OBLED, I973).

b) Résidus protéiques.

Plasma, autres compartiments.

Les résidus de l'extraction par l'ATC Io p. Ioo sont neutralisés et dégraissés selon une méthode déjà citée (ARNAL et al., I97I).

\section{Extraction des protéines musculaives.}

Les protéines musculaires sont extraites selon la méthode de Heldaxder (1957). Le détail de la technique a été décrit par ailleurs (OBLED, 1973). Les protéines sarcoplasmiques sont solubilisées dans le tampon phosphate $0,03 \mathrm{M}\left(\mathrm{pH}_{7,4}\right)$, puis les protéines myofibrillaires sont extraites par une solution de KI I,IM dans le tampon phosphate o, IM $\left(\mathrm{pH}_{7,4}\right)$. Le résidu constitue le stroma.

La myosine est obtenue à partir de la solution contenant les protéines myofibrillaires. Après diminution de la force ionique, le précipité, séparé par centrifugation est remis en solution dans une solution tamponnée (tris $\mathrm{HCl}$ o,o2 $\mathrm{M}$ pH $7,4 \mathrm{HCl}$ o,6, $\mathrm{Mg} \mathrm{Cl}_{2}$ Io $^{-3} \mathrm{M}$ ). L'actomyosine est 
dépolymérisée en présence de pyrophosphate et la myosine est séparée par ultracentrifugation $2 \mathrm{~h}$ à IOO OOO $g$ (OBLED, I973).

L'ensemble troponine tropomyosine est extrait directement à partir du muscle selon la méthode de Szent Gyorgi (I963). La méthode a été détaillée par ailleurs (OBLed, I973). Après lavage du muscle par une solution de bicarbonate o,o3 M, le culot mis en suspension dans $\mathrm{NaCl}$ $0,05 \mathrm{M}$ est chauffé à $60^{\circ} \mathrm{C}$. Le filtrat est dialysé contre de l'eau distillée. Le complexe troponine tropomyosine est partiellement purifié par précipitation à $\mathrm{pH} 5$ et redissolution à $\mathrm{pH} 7$.

L'azote protéique est dosé au niveau de chaque fraction par microkjeldahl.

\section{c) Séparation et dosage des acides aminés.}

Les extraits contenant les acides aminés libres sont d'abord purifiés par passage sur résine échangeuse de cations (Amberlite IR I 20). La radioactivité des composés non retenus sur la colonne (effluent) est mesurée. Les acides aminés sont élués par $\mathrm{NH}_{4} \mathrm{OH}{ }_{4} \mathrm{~N}$. Ils sont séparés et dosés sur un analyseur selon une version accélérée de la méthode de Moore et al. (I958).

\section{d) Mesure de l'activité catheptasique $D$ (3.4.4.23) totale du foie et du muscle.}

La méthode utilisée est celle de Anson modifiée par VALIN (1967). Les échantillons sont broyés dans la solution de triton tamponnée, de façon à faire éclater les lysosomes. Après centrifugation ( $5 \mathrm{mn}, 5$ ooo g), l'activité du surnageant est déterminée par incubation à $37^{\circ} \mathrm{C}$ en présence d'une solution d'hémoglobine. La réaction est stoppée par addition d'ATC I 5 p. Ioo. Après centrifugation, la densité optique du surnageant est lue à $280 \mathrm{~m} \mu$ contre le temps zéro. L'activité catheptasique D totale de l'échantillon est exprimée en densité optique/g tissu/heure.

\section{6. - Mesure de la radioactivité}

La radioactivité des échantillons est mesurée par scintillation liquide au moyen d'un spectromètre Packard Tricarb 3375. Les mesures radiochromatographiques de la L-lysine-14C sont effectuées dès la sortie de la colonne de l'analyseur automatique grâce à un spectromètre à cellule d'anthracène (Packard Flow Detector).

Les techniques, décrites précédemment par ArNal et al. (I97I) ont été appliquées avec les modifications suivantes. Le mélange scintillant utilisé est l'Instagel. Les résidus protéiques sont solubilisés dans $\mathrm{NaOH}$ o, 8N (OBLED, 1973). Le stroma, insoluble dans la soude dans ces conditions, est hydrolysé par $\mathrm{HCl} 6 \mathrm{~N}$ (OBLED, 1973).

$$
\text { 7. - Mesure } d u{ }^{14} \mathrm{CO}_{2}
$$

L'animal est placé dans une chambre d'un litre de volume, balayée par un courant d'air. La quantité de gaz carbonique expiré par l'animal est mesurée par un analyseur à infrarouge Hartman-Braun et recueillie ensuite dans une solution de soude $0,8 \mathrm{~N}$. La radioactivité de cette solution est mesurée (OBLED, 1973).

$$
\text { 8. - Expression des résultats }
$$

Trois modes d'expression ont été utilisés :

- le p. roo de la dose injectée;

- les désintégrations par minute et par gramme de tissu frais corrigées pour une même dose injectée de ro $\mu \mathrm{Ci}$ et un même poids vif à l'abattage de $200 \mathrm{~g}$;

- la radioactivité spécifique (RAS) : désintégrations par minute et par mg de lysine, corrigées comme précédemment.

9. - Mesure des synthèses protéiques,

calcul du temps de renouvellement des protéines

Selon Reboud et al. (1966), VANDeRmeERs et al. (1967), la vitesse de synthèse des protéines est d'ordre o alors que la vitesse de dégradation et d'exportation est d'ordre $\mathbf{I}$. La variation instantannée $\mathrm{dN} / \mathrm{d} t$ de la radioactivité $\mathrm{N}$ liée aux protéines, exprimée en d.p.m./g tissu, est de la forme 


$$
\frac{\mathrm{dN}}{\mathrm{d} t}=\mathrm{Ks} r(t)-\mathrm{K}_{\mathrm{E}+\mathrm{D}} \mathrm{N}
$$

Où $\mathrm{K} s$ est la constante d'incorporation du précurseur, $\mathbf{K}_{\mathrm{E}+\mathrm{D}}$ la constante de vitesse commune à l'exportation et à la dégradation des protéines et $r$ la RAS du précurseur dans le tissu.

Deux méthodes de calcul de la constante d'incorporation Ks ont été utilisées.

a) Appareil digestif, foie.

Les valeurs de $\mathrm{K} s$ sont calculées à partir de l'équation simplifiée (2) $\mathrm{dN} / \mathrm{d} t=\mathrm{K} s \quad r(t)$, étant donné que le deuxième terme de l'équation (I) est négligeable pendant les 20 mn qui suivent l'injection du précurseur (VANDERmeERs et al., I967). Après intégration de cette équation, la valeur de $\mathrm{K} s$ est déduite de l'équation.

$$
\mathbf{K} s=\frac{\mathrm{N}}{\int_{t_{1}}^{t_{2}} r(t) \mathrm{d} t}
$$

Où $\mathrm{N}$ représente l'accroissement de la radioactivité des protéines totales.

La fonction $r(t)$ décroit selon une loi sensiblement exponentielle et la valeur de l'intégrale est déterminée par la méthode des trapèzes. Il est possible également d'utiliser comme valeur de l'intégrale, la RAS de la lysine libre au temps $\frac{t_{1}+t_{2}}{2}$, obtenue sur la courbe d'évolution de la RAS au cours du temps en coordonnées semi-logarithmiques. La valeur obtenue diffère peu de la précédente. Dans le cas de l'appareil digestif et du foie, l'intervalle utilisé est o- $5 \mathrm{mn}$ et la valeur de la RAS de la lysine libre au temps 7,5 mn après l'injection est obtenue par extrapolation de la droite d'évolution de la RAS tracée en coordonnées semi-logarithmiques entre les temps I 5 et $30 \mathrm{mn}$.

\section{b) Muscle.}

Le second calcul consiste à expliquer d'abord $\mathrm{N}(t)$, en l'identifiant pendant la durée de l'expérience à une fonction bien définie, de façon à déterminer ensuite la fonction dérivée. La correspondance empirique simple la meilleure est obtenue par une fonction du type $\mathrm{N}=\mathrm{A}$ Lnt - $b$ (4), comme Vandermerrs et al. (I968) l'ont montré dans le cas du pancréas. Nous l'avons vérifié dans le cas du muscle, la radioactivité des protéines s'élève linéairement en fonction du temps porté en échelle logarithmique décimale. Les équations des droites de regression ont été calculées par la méthode des moindres carrés. Ia signification de la pente (A) a été testée (test $t$ ) (SNEDECOR et COCHRAN, I957). Les pentes des droites de régression sont en général significatives au seuil 0,05 .

Connaissant l'équation (4), il est possible de calculer la dérivée $\mathrm{dN} / \mathrm{d} t=\frac{\mathrm{A}}{t}$ (5). L'équation (I) devient

$$
\frac{\mathrm{A}}{t}=\mathrm{K} s r(t) \rightarrow \mathrm{K}_{\mathrm{E}+\mathrm{D}} \mathrm{N}
$$

Il est possible de calculer l'équation de régression de A/t selon les deux variables explicatives $r$ et $\mathrm{N}$. L'ajustement de la régression aux points expérimentaux, non significative (test $F$ ) (SNEDECOR et COCHRAN, I957) lorsque $r(t)$ représente la RAS de la lysine libre du muscle, le devient (seuil 0,05 ) lorsque $r(t)$ représente la RAS de la lysine libre du plasma. Dans ce cas, l'écart type des coefficients estimés par la régression multiple peut être calculé et leur signification testée (test $t$ ). La constante $K_{\mathrm{E}+\mathrm{D}}$ n'est pas significative, ce qui indique que la variable $\mathrm{N}$ n'est pas explicative.

L'équation (6) se résume à $\mathrm{A} / t=\mathrm{K} s(t)$, régression $\mathrm{A} / t$ en $r(t)$. La constante $\mathrm{K} s$ et son écart type sont déterminés. La constante $K s$ est significative au seuil 0,05 (test $t$ ).

Connaissant la teneur en lysine des protéines du tissu et la teneur en protéines des poudres, il est aisé de calculer la quantité de protéines synthétisées. La quantité totale de protéines du tissu rapportée à la quantité synthétisée par unité de temps nous donne le temps de renouvellement. 


\section{TABLEAU I}

Expression des résultats : moyenne et écart-type de la population

\begin{tabular}{|c|c|c|c|}
\hline & & Lot ad libitum & Lot repas \\
\hline \multicolumn{2}{|c|}{$\begin{array}{l}\text { Gain de poids moyen } \\
\text { sur la période expérimentale }(\mathrm{g} / \mathrm{j})\end{array}$} & $6,7 \pm 0,9$ & $6,7 \pm 1,2$ \\
\hline \multicolumn{2}{|c|}{$\begin{array}{c}\text { Quantité moyenne ingérée sur la période } \\
\text { expérimentale (g MS/rat/j) }\end{array}$} & 17,3 & 15,8 \\
\hline \multicolumn{2}{|c|}{$\begin{array}{l}\text { Quantité moyenne ingérée entre } 190 \\
\text { et } 200 \mathrm{~g}(\mathrm{~g} \mathrm{MS} / \mathrm{rat} / \mathrm{j})\end{array}$} & ${ }^{*} 19,3 \pm 1,4$ & $* 17,7 \pm 1,2$ \\
\hline \multirow{2}{*}{ Poids moyen du foie (g) } & Jour & $10,1 \pm 0,6$ & $9,9 \pm 0,4$ \\
\hline & Nuit & $9,3 \pm 1,2$ & $9,4 \pm 0,7$ \\
\hline \multirow{2}{*}{$\begin{array}{c}\text { Poids moyen } \\
\text { de l'appareil digestif }(g)\end{array}$} & Jour & $13,1 \pm 1,1$ & $12,8 \pm 1,2$ \\
\hline & Nuit & $13,1 \pm 0,9$ & $13,8 \pm 1,2$ \\
\hline
\end{tabular}

* Signification de la différence entre le lot ad libitum et le lot repas d'après le test $t^{\prime}>t$ (SNEDECor et Cochran, 1957) au seuil 0,02 .

\section{TABLEAU 2}

Poids du contenu de l'estomac (g sec.) en fonction de l'heure et du rythme alimentaire des rats Moyenne et écart-type de la population

\begin{tabular}{|c|c|c|c|c|c|c|c|c|c|}
\hline \multicolumn{2}{|r|}{ Heure } & $15 \mathrm{~h} 15$ & $15 \mathrm{~h} 30$ & $16 \mathrm{~h}$ & $17 \mathrm{~h}$ & 23 h 15 & $23 \mathrm{~h} 30$ & $0 \mathrm{~h}$ & $1 \mathrm{~h}$ \\
\hline \multirow[t]{2}{*}{$\begin{array}{l}\text { Lot ad } \\
\text { libitum }\end{array}$} & $\begin{array}{c}\text { Contenu de } \\
\text { l'estomac }(g \text { sec })\end{array}$ & $\begin{array}{r}1,5 \\
\pm 0,5\end{array}$ & $\begin{array}{r}0,7 \\
+0,7\end{array}$ & $\begin{array}{r}0,7 \\
\pm 0,4\end{array}$ & $\begin{array}{r}0,5 \\
\pm 0,2\end{array}$ & $\begin{array}{r}2,2 \\
\pm 0,7\end{array}$ & $\begin{array}{r}1,7 \\
\pm 1,3\end{array}$ & $\begin{array}{r}1,4 \\
+\quad 0,4\end{array}$ & $\begin{array}{r}1,7 \\
\pm \quad 0,5\end{array}$ \\
\hline & $\begin{array}{c}\text { repas 1'y h } 30 \\
\text { Contenu de } \\
\text { l'estomac }(\mathrm{g} \mathrm{sec})\end{array}$ & & & $\begin{array}{r}2,8 \\
+\quad 0,6\end{array}$ & $\begin{array}{r}\text { repas } \\
1,3 \\
\pm 0,3\end{array}$ & $\begin{array}{r}2 h 30 \\
1,9 \\
+\quad 0,7\end{array}$ & $\begin{array}{r}1,2 \\
\pm 0,9\end{array}$ & & \\
\hline Lot repas & $\frac{\text { Contenu }}{\text { Ingéré }} \times 100$ & & & 79 & 38 & 56 & 34 & & \\
\hline
\end{tabular}




\section{RÉSULTATS}

\section{I. - Croissance et consommation des animaux (tabl. I et 2, fig. I)}

Les croissances moyennes des animaux des deux lots ne sont pas significativement différentes.Pour une même croissance de $6,7 \mathrm{~g} /$ jour, les animaux du lot repas ont consommé significativement moins que ceux du lot témoin, $6 \mathrm{p}$. Ioo entre r9o et $200 \mathrm{~g}$.

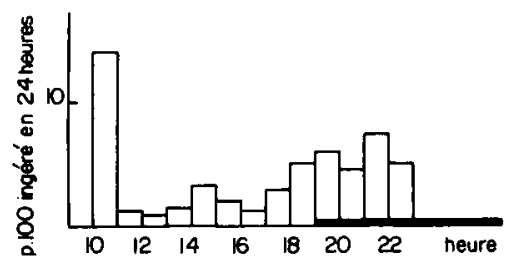

FlG. $_{1}$. - Rythme de consommation au cours du nycthémève de rats nourris ad libitum, en $p .100$ de la quantité ingérée en 24 heures en frais

La cinétique de consommation des animaux du lot témoin au cours du nycthémère indique que la quantité consommée durant la phase claire ne représente que 30 p. roo de la quantité totale ingérée en 24 heures. Durant les quatre premières heures de la phase sombre, les animaux de ce lot consomment 25 p. Ioo de la quantité totale ingérée en 24 heures.

Les poids du foie et de l'appareil digestif des différents groupes expérimentaux ne sont pas significativement différents (tabl. I).

Le poids sec du contenu stomacal des animaux du lot ad libitum est environ 2 fois plus élevé le jour que la nuit. La valeur élevée à $I_{5} \mathrm{~h}$ I5 provient du repas que les animaux ont pris entre $\mathrm{I}_{4}$ et $\mathrm{I}_{5} \mathrm{~h}$. Malgré un rythme de consommation identique le jour et la nuit, le poids sec du contenu de l'estomac des animaux du lot repas est plus faible la nuit que le jour. La vidange stomacale est donc plus rapide chez ces animaux durant la phase sombre.

\section{2. - Teneur en lysine libre des différents tissus (tabl. 3)}

Quel que soit le mode d'alimentation et 1'heure des mesures (jour ou nuit) la teneur en lysine libre du muscle est environ 3 à 5 fois plus élevée que celle des autres compartiments.

Dans chaque lot, les teneurs en lysine libre de l'appareil digestif et du muscle ne sont pas significativement différentes entre les groupes jour et nuit. Dans le plasma, les teneurs sont diminuées chez les groupes nuit, respectivement de 18 et 27 p. Ioo pour le lot ad libitum et pour le lot repas. Dans le foie au contraire la teneur en lysine est augmentée chez les groupes nuit, respectivement de 40 et de 30 p. IoO pour le lot ad libitum et pour le lot repas.

Les teneurs en lysine libre du plasma et du muscle sont voisines dans les deux lots d'animaux. Par contre dans le foie et l'appareil digestif, elles sont plus élevées respectivement de 20 p. Ioo et $\mathrm{I} 8 \mathrm{p}$. Ioo pour le lot ad libitum que pour le lot repas. 
Teneur en lysine libre des différents tissus ( $\mathrm{mg} / \mathrm{loo} \mathrm{g}$ ) Moyenne et écart-type de + valeurs,

chaque valeur représente un échantillon de 3 à 6 rats

\begin{tabular}{|c|c|c|c|c|}
\hline & \multicolumn{2}{|c|}{ Lot ad libitum } & \multicolumn{2}{|c|}{ Lot repas } \\
\hline & Jour & Nuit & Jour & Nuit \\
\hline Plasma . . . . . . . . & $8,5 \pm 1,5$ & $7,0 \pm 0,9$ & $x, x=1,7$ & $6,4 \div-1,0$ \\
\hline Foie $\ldots \ldots \ldots \ldots \ldots$ & $10,9 \pm 2,7$ & $14,2 \pm 1,9$ & $x, 7=2,7$ & $11,3 \div 2,2$ \\
\hline Appareil digestif $\ldots \ldots \ldots$ & $8,6 \pm 0,9$ & $8,4 \pm 0,9$ & $7,0=1,3$ & $6,9 \pm 1,7$ \\
\hline Muscle $\ldots \ldots \ldots \ldots \ldots$ & $35,3 \pm 5,9$ & 32,9 & 32,3 & 30,8 \\
\hline
\end{tabular}
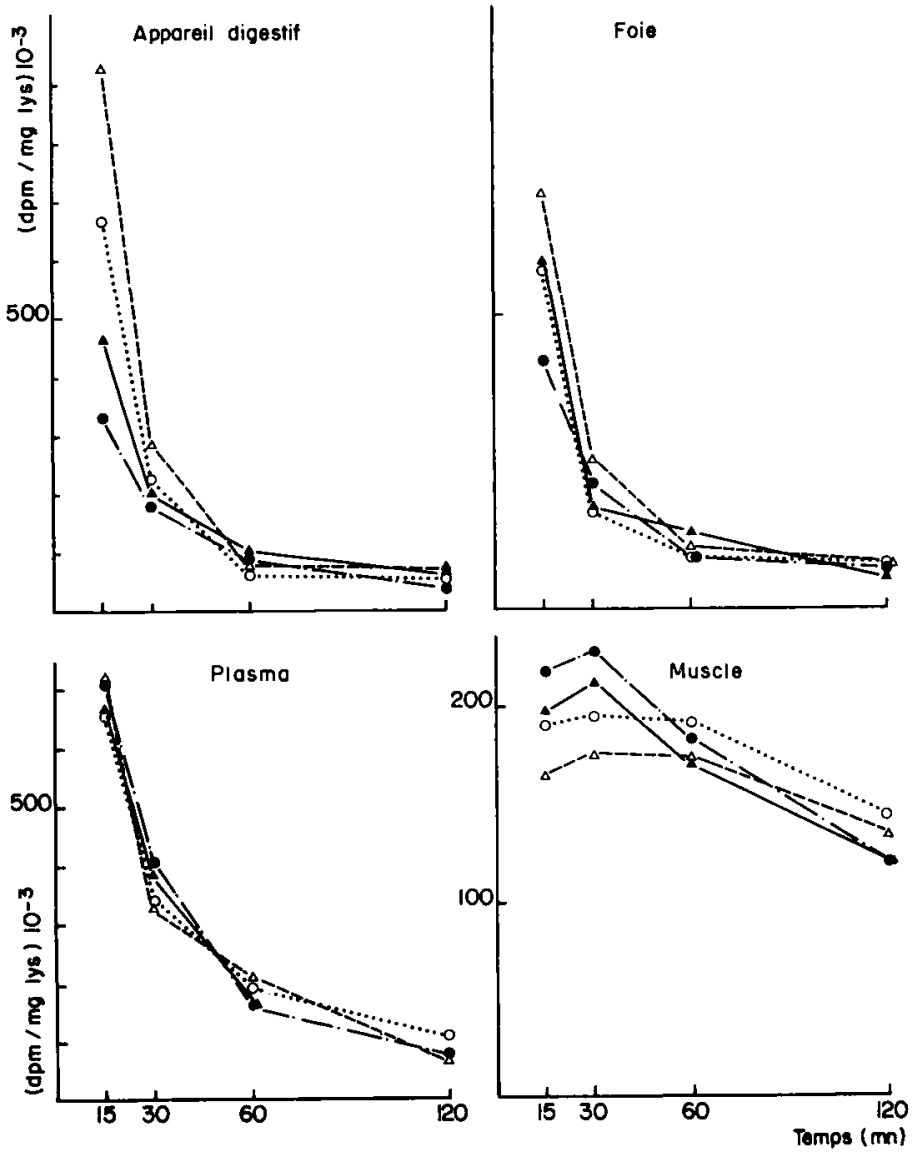

FIG. 2. - Évolution de la radioactivité spécifique de la L-lysine- ${ }^{14} C$ libre [(R. A. S. : (dpm/mg lys)] dans divers tissus selon le rythme de consommation et l'heure d'injection de la L-lysine-14C

..... o lot ad libitum groupe jour $\Delta \ldots . . \Delta$ lot repas groupe jour $\bullet-\cdot-\bullet$ lot ad libitum groupe nuit $\triangle$ L lot repas groupe nuit 


\section{3. - Évolution de la radioactivité spécifique \\ de la L-lysine ${ }^{14} \mathrm{C}$ libre des divers compartiments \\ en fonction de l'heure d'injection et du rythme alimentaire (fig. 2)}

Contrairement aux autres compartiments, la RAS de la L-lysine--14 $\mathrm{C}$ du muscle varie peu pendant l'intervalle de temps considéré. Au temps $I_{5}$ minutes, elle est environ 3 à 4 fois plus faible que celle des autres compartiments pour leur devenir supérieure au temps I20 minutes.

Quinze minutes après 1'injection, les RAS de la L-lysine- ${ }^{14} \mathrm{C}$ libre du foie et de 1'appareil digestif sont plus élevées le jour que la nuit, respectivement de $\mathrm{I}_{5}$ et 49 p. Ioo pour le lot repas, et de 27 et 46 p. Ioo pour le lot ad libitum. Dans le plasma et le muscle, les différences sont peu significatives.

Dans le foie et surtout dans l'appareil digestif, la RAS de la lysine est plus élevée pour le lot repas que pour le lot ad libitum au temps $15 \mathrm{mn}$. Les différences sont peu significatives dans le plasma et le muscle.

4. - Évolution de la radioactivité incorporée dans les protéines des divers compartiments en fonction de l'heure d'injection et du rythme alimentaire

a) Plasma. Appareil digestif, foie (fig. 3).

La radioactivité incorporée dans les protéines de ces compartiments est en général plus élevée durant la phase sombre que durant la phase claire, et plus élevée pour le lot ad libitum que pour le lot repas, surtout aux temps $\mathrm{r}_{5}$ et 30 minutes.

L'incorporation du précurseur est toujours plus 'élevée dans les protéines du foie et de l'appareil digestif des animaux du lot ad libitum groupe nuit que dans celles des 3 autres lots : au point 30 minutes, respectivement $r, 8$ fois plus et $\mathrm{I}, 3$ fois plus.

b) Muscle (fig. 4).

Dans l'équation des droites de régression $(\mathrm{N}=a \operatorname{logt}-b)$, $a$ et $b$ sont grossièrement du même ordre de grandeur. Le rapport $b / a$ donnant l'abscisse à l'origine, est voisin de I; toutes les droites ont donc une abscisse à l'origine commune, voisine de ro minutes.

La quantité de radioactivité incorporée dans les protéines sarcoplasmiques et myofibrillaires est voisine et 2 à 3 fois plus élevée que celle incorporée dans les protéines du stroma.

Pour chaque fraction, les régressions linéaires ont été comparées deux à deux par analyse de la covariance et test $\mathrm{F}$ bilatéral, permettant la comparaison des variances, des pentes et des niveaux (SNEDECOR et COCHRAN, 1957).

Les pentes des droites de regression, traduisant la cinétique d'incorporation du précurseur dans les protéines totales, ne sont pas significativement différentes; cependant, la quantité de radioactivité incorporée dans les protéines totales est plus élevée pour le lot ad libitum groupe nuit que pour le lot repas groupe nuit (niveatux setil 0,025 ).

Des différences sont notées dans les fractions protéiques suivantes. Dans les 

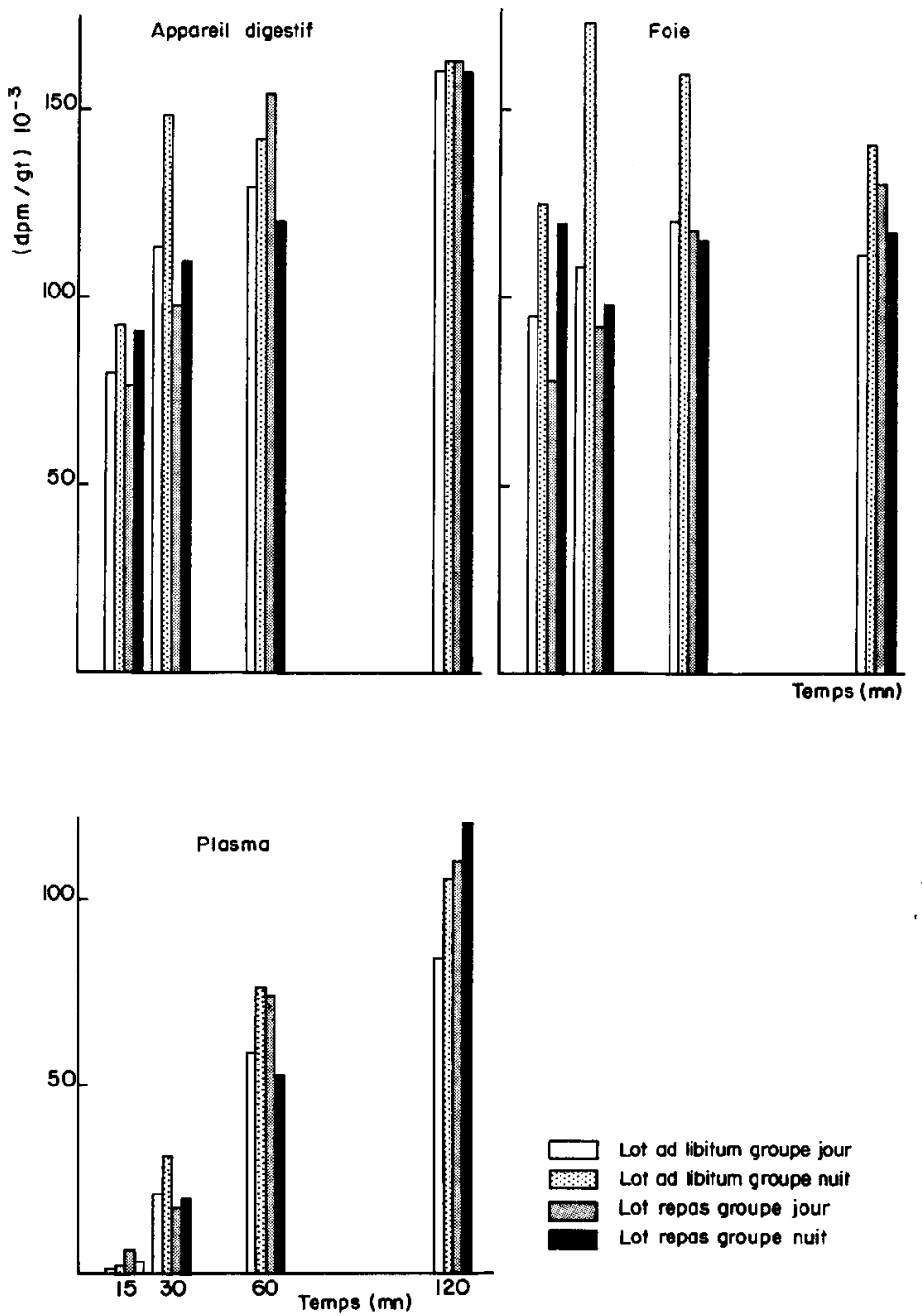

FIG. 3. - Évolution de la radio-activité acido-insoluble $(\mathrm{dpm} / \mathrm{gt}) \mathrm{Io}^{-3}$ dans divers tissus selon le rythme de consommation et l'heure d'injection de la L-lysine-14C 


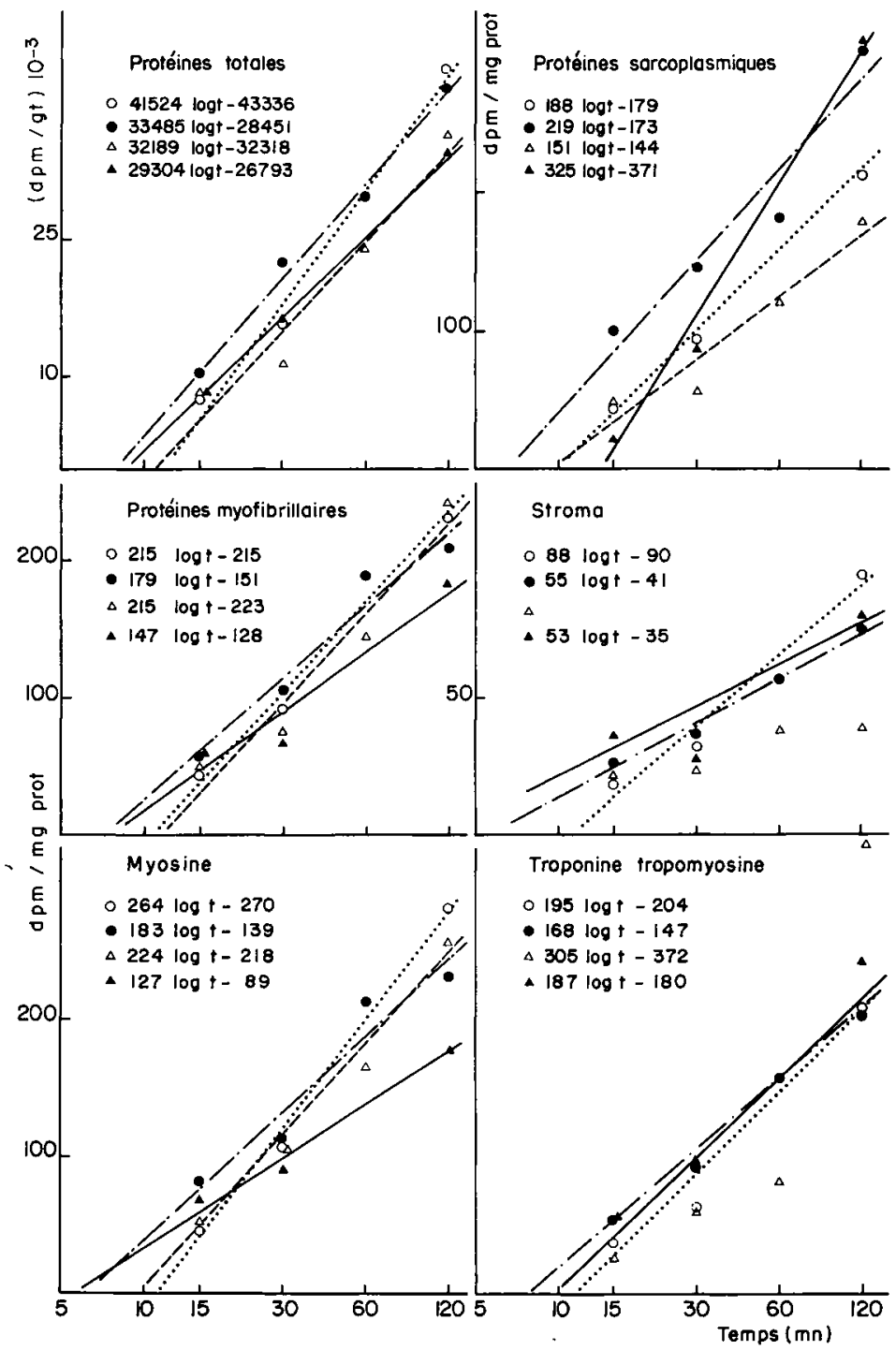

Fıg. 4. - Évolution de la radioactivité incorporée dans les protéines totales du muscle (dpm/gt) Io ${ }^{-3}$ et dans différentes fractions protéiques du muscle (dpm/mg protéine) en fonction du temps porté en échelle logarithmique décimale

Droites de régression .... points expérimentaux o Lot ad libitum groupe jour

$$
\begin{array}{lll}
-\cdots- & \text { et } & \text { Lot ad libitum groupe nuit } \\
\cdots & \text { équations } & \Delta \text { Lot repas groupe jour } \\
- & & \Delta \text { Lot repas groupe nuit }
\end{array}
$$


deux lots d'animaux, la quantité de radioactivité incorporée dans les protéines sarcoplasmiques est plus élevée la nuit que le jour (niveaux au seuil 0,05: lot ad libitum, pentes seuil 0,025 : lot repas).

La pente de la droite d'incorporation de la radioactivité dans les protéines du stroma du lot ad libitum est significativement plus élevée le jour que la nuit $(0,05<p$ $<0, \mathrm{I}$ ). Il en est de même pour la myosine dans le cas du lot repas (seuil o,05). De plus la quantité de radioactivité incorporée dans la myosine est plus élevée pour le lot ad libitum groupe nuit que pour le lot repas groupe nuit (niveaux seuil 0,05 ).

\section{5. - Anabolisme protéique dans les divers compartiments en fonction de l'heure d'injection et du rythme alimentaire}

a) Foie, appareil digestif (tabl. 4).

La quantité de protéines synthétisées est environ 2 fois plus élevée la nuit que le jour, quel que soit le lot et le tissu considérés. La constante de synthèse $\mathrm{Ks}$ est plus élevée dans le lot ad libitum que dans le lot repas.

\section{TABLEAU 4}

Ks (mg protéines synthétisées/heure/g tissu)

et temps de renouvellement des protéines de divers tissus

en fonction de l'heure d'injection de la L-lysine-14C et le rythme de consommation

\begin{tabular}{|c|c|c|c|c|c|}
\hline & & \multicolumn{2}{|c|}{ Lot ad libitum } & \multicolumn{2}{|c|}{ Lot repas } \\
\hline & & Jour & Nuit & Jour & Nuit \\
\hline Foie & $\begin{array}{l}\mathrm{Ks} \\
\operatorname{Tr}(\mathrm{h})\end{array}$ & $\begin{array}{r}4,4 \\
34,5\end{array}$ & 9 & $\begin{array}{l}2,9 \\
49\end{array}$ & $\begin{array}{r}5 \\
29\end{array}$ \\
\hline Appareil digestif & $\begin{array}{l}\mathrm{Ks} \\
\mathrm{Tr}_{\mathrm{r}}(\mathrm{h})\end{array}$ & $\begin{array}{r}3,4 \\
29,5\end{array}$ & $\begin{array}{r}9 \\
11\end{array}$ & $\begin{array}{l}3,2 \\
32\end{array}$ & $\begin{array}{r}6,3 \\
16,5\end{array}$ \\
\hline $\begin{array}{l}\text { Protéines totales } \\
\text { du muscle }\end{array}$ & $\begin{array}{l}\mathrm{K} s \\
\operatorname{Tr}(\mathrm{j})\end{array}$ & $\begin{array}{c}1,18 \pm 0,02 \\
6,3 \pm 0,1\end{array}$ & $\begin{array}{l}0,88 \pm 0,05 \\
8,4 \pm 0,5\end{array}$ & $\begin{array}{c}0,86 \pm 0,05 \\
8,6 \pm 0,5\end{array}$ & $\begin{array}{c}0,81 \pm 0,05 \\
9,-2 \pm 0,6\end{array}$ \\
\hline $\begin{array}{c}\text { Protéines } \\
\text { sarcoplasmiques }\end{array}$ & $\begin{array}{l}\mathrm{K} s \\
\mathrm{~T} r(\mathrm{j})\end{array}$ & $\begin{array}{c}0,26 \pm 0,01 \\
9,1 \pm 0,4\end{array}$ & $\begin{array}{c}0,28 \pm 0,02 \\
8,4 \pm 0,6\end{array}$ & $\begin{array}{l}0,20 \pm 0,01 \\
11,8 \pm 0,6\end{array}$ & $\begin{array}{c}0,44 \pm 0,03 \\
5,4 \pm 0,4\end{array}$ \\
\hline $\begin{array}{c}\text { Protéines } \\
\text { mvofibrillaires }\end{array}$ & $\begin{array}{l}\mathrm{Ks} \\
\mathrm{Tr}(\mathrm{j})\end{array}$ & $\begin{array}{c}0,59 \pm 0,01 \\
7,3 \pm 0,1\end{array}$ & $\begin{array}{c}0,46 \pm 0,012 \\
9,3 \pm 0,4\end{array}$ & $\begin{array}{c}0,56 \pm 0,03 \\
7,7 \pm 0,4\end{array}$ & $\begin{array}{c}0,39 \pm 0,033 \\
11 \pm 0,8\end{array}$ \\
\hline Stroma & $\begin{array}{l}\mathrm{K} s \\
\mathrm{Tr}(\mathrm{j})\end{array}$ & $\begin{array}{c}0,068 \pm 0,001 \\
9,8 \pm 0,1\end{array}$ & $\begin{array}{c}0,038 \pm 0,002 \\
17,5 \pm 0,9\end{array}$ & & $\begin{array}{c}0,039 \pm 0,003 \\
17,1 \pm 1,3\end{array}$ \\
\hline Myosine & $\begin{array}{l}\mathrm{Ks} \\
\operatorname{Tr}(\mathrm{j})\end{array}$ & $\begin{array}{c}0,45 \pm 0,01 \\
7,3 \pm 0,2\end{array}$ & $\begin{array}{l}0,29 \pm 0,02 \\
11,3 \pm 0,8\end{array}$ & $\begin{array}{c}0,36 \pm 0,02 \\
9,1 \pm 0,5\end{array}$ & $\begin{array}{l}0,21 \pm 0,0: 2 \\
15,6 \pm 1,5\end{array}$ \\
\hline $\begin{array}{c}\text { Troponine } \\
\text { Tropomyosine }\end{array}$ & $\begin{array}{l}\mathrm{Ks} \\
\operatorname{Tr}(\mathrm{j})\end{array}$ & $\begin{array}{c}0,043 \pm 0,001 \\
7,5 \pm 0,2\end{array}$ & $\begin{array}{c}0,035 \pm 0,002 \\
9,2 \pm 0,5\end{array}$ & $\begin{array}{c}0,064 \pm 0,004 \\
5 \pm 0,3\end{array}$ & $\begin{array}{c}0,041 \pm 0,003 \\
7,8 \pm 0,1\end{array}$ \\
\hline
\end{tabular}


b) Muscle (tabl. 4).

Les constantes d'incorporation $\mathrm{K} s$, pentes des régressions linéaires $\mathrm{A} / t=\mathrm{K} s \boldsymbol{r}(t)$, ont été comparées par test F bilatéral (SNEDECOR et CoCHRAN, I957).

Protéines totales.

Pour le lot ad libitum, la quantité de protéines synthétisées est significativement plus élevée le jour que la nuit; pour le lot repas, elle n'est pas significativement différente. La valeur du $\mathrm{K} s$, plus élevée pour le lot ad libitum groupe jour que pour le lot repas groupe jour, n'est pas significativement différente pour les groupes nuit.

\section{Différentes fractions protéiques.}

Les protéines du muscle, se classent en deux catégories. L,a quantité de protéines sarcoplasmiques synthétisées est plus élevée la nuit que le jour, essentiellement dans le lot repas. La valeur du Ks pour les autres protéines est toujours plus élevée durant la phase sombre.

I, a constante d'incorporation du précurseur dans les protéines sarcoplasmiques est plus élevée de $30 \mathrm{p}$. Ioo pour le lot ad libitum groupe jour que pour le lot repas groupe jour. Dans le cas des protéines myofibrillaires, la valeur du Ks est plus élevée de 18 p. roo pour le lot ad libitum groupe nuit que pour le lot repas groupe nuit. La quantité de myosine synthétisée est toujours plus importante chez les animaux du lot ad libitum que chez les animaux du lot repas : respectivement de 24 et $39 \mathrm{p}$. Ioo durant la phase claire et durant la phase sombre.

Par contre, la constante d'incorporation du précurseur dans les protéines sarcoplasmiques est plus élerée de $57 \mathrm{p}$. Ioo pour le lot repas groupe nuit que pour le lot ad libitum. La quantité de troponine tropomyosine synthétisée est toujours plus élevée chez les animaux du lot repas que chez les animaux du lot ad libitum : respectivement de 49 et $\mathrm{I} 7 \mathrm{p}$. roo durant la phase claire et la phase sombre.

La quantité de protéines du stroma synthétisées n'est pas significativement différente dans les deux lots.

\section{6. - Catabolisme protéique: activité catheptasique $D$ totale (tabl. 5)}

L'activité catheptasique $\mathrm{D}$ du foie est plus élevée de I 8 p. Ioo le jour que la nuit pour le lot ad libitum. A l'opposé, chez les animaux du lot repas, le foie a une activité plus élevée de 20 p. roo la nuit que le jour. Quel que soit le lot, entre jour et nuit, les activités ne sont pas significativement différentes dans le muscle.

Dans tous les cas, l'activité des tissus du lot ad libitum est supérieure à celle des tissus du lot repas, de $90 \mathrm{p}$. Ioo dans le muscle et de $28 \mathrm{p}$. Ioo dans le foie, en moyenne.

\section{7. - Catabolisme oxydatif de la L-lysine-14C}

Le pourcentage de radioactivité injectée retrouvé dans le gaz carbonique au bout de 8 heures est plus élevé la nuit que le jour dans les deux lots : 9, I p. Ioo contre 8,2 p. Ioo pour le lot ad libitum et 8,2 p. Ioo contre $7,2 \mathrm{p}$. Ioo pour le lot repas. Il est en moyenne plus élevé pour le lot ad libitum que pour le lot repas. 
TABLEAU 5

Activité catheptasique $D$ totale par $G$ de tissu (densité optique/g tissu/heure)

Moyenne et écart-type de 4 valeurs,

chaque valeur représente un échantillon de 3 à 6 rats

\begin{tabular}{c|c|c|c|c}
\hline Lour & Nuit & \multicolumn{2}{|c}{ Lot repas } \\
\hline Foie & Jour & Nuit \\
\hline Muscle & $6,60 \pm 1,05$ & $5,60 \pm 0,30$ & $4,30 \pm 0,30$ & $5,20 \pm 0,2$ \\
\hline $2,30 \pm 0,45$ & $1,95 \pm 0,25$ & $1,10 \pm 0,15$ & $1,15 \pm 0,15$ \\
\hline
\end{tabular}

\section{DISCUSSION}

\section{I. - Critique de la méthode}

a) Mode d'injection, sélection des animaux et méthode expérimentale.

L'injection intrapéritonéale a été choisie parce qu'elle est rapide, facile à mettre en œuvre et qu'elle ne nécessite pas une contention particulière des animaux, comme l'injection intraveineuse. D'autre part, la résorption est assez rapide. VANDERMEERS et al. (I967) ont montré que, 5 minutes après l'injection IP de leucine- ${ }^{14} \mathrm{C}$, la radioactivité libre du plasma a déjà atteint sa valeur maximale.

De nombreux auteurs ont souligné l'importance d'une bonne synchronisation des animaux sur le plan alimentaire, de façon à diminuer les variations d'état métabolique et obtenir des lots expérimentaux plus homogènes. Pour maitriser ce facteur expérimental, les animaux peuvent être mis au jeûne durant la phase claire (PoTTER et al., I966; Symmons et al., I972). Cette méthode modifie le rythme alimentaire normal et ne convient pas à notre étude. Nous avons injecté le marqueur après un petit repas, lorsque l'animal est en cours de digestion et en phase d'absorption des nutriments, ce qui assure une bonne dilution du marqueur dans l'organisme. Dans ce but, la mangeoire des animaux du lot ad libitum est retirée I heure et remise dans la cage une heure avant l'injection. Pour les animaux du lot repas, l'injection est pratiquée une demi-heure après le repas.

Malgré cette précaution, des différences entre animaux peuvent être observées, provenant essentiellement de l'injection du précurseur (LEwIs et al., I966). C'est pourquoi nous avons cherché à constituer, pour un point expérimental donné, un groupe de rats aussi homogène que possible, non seulement du point de vue de la croissance, mais aussi du point de vue de l'activité métabolique, estimée par la mesure de la radioactivité de différentes fractions plasmatiques. Cette méthode, dont le détail a été exposé par ailleurs (OBLED, I973), est facile à mettre en œuvre à condition de disposer d'un nombre suffisant d'animaux, au moins 6 par point expérimental. 
Cette étude a été réalisée à l'aide de deux points expérimentaux seulement, ce qui est insuffisant pour définir le rythme nycthéméral de la synthèse protéique. La modification du comportement alimentaire des animaux de lot repas a pu entraîner un déplacement du minimum et $\mathbf{d u}$ maximum de la synthèse protéique déterminés sur des rats placés en libre consommation (Fishman et al., I969; LE Bouton et HANDLER, I970). Cependant, les observations effectuées sur la vidange stomacale des animaux du lot repas, faisant apparaître un transit plus rapide la nuit que le jour, semblent montrer que les rythmes sont maintenus, même avec l'alimentation contrôlée.

b) Méthodes analytiques.

Ces méthodes ont été critiquées par ailleurs (OBLED, I973). Pour contrôler la bonne extraction des protéines musculaires, nous avons mesuré l'azote protéique de chaque fraction. La quantité d'azote extraite dans chaque fraction protéique (sarcoplasme-myofibrilles-stroma) se rapproche de façon convenable des valeurs citées par les auteurs $(56,7 \mathrm{mg}$ protéines sarcoplasmiques, I03 mg protéines myofibrillaires et $\mathrm{I} 6 \mathrm{mg}$ stroma pour I $\mathrm{g}$ de tissu). Le coefficient de variation est de $5 \mathrm{p}$. Ioo pour les protéines myofibrillaires, I $8 \mathrm{p}$. Ioo pour les protéines sarcoplasmiques et 24 p. Ioo pour le stroma. Ces variations peuvent provenir d'une hétérogénéité des échantillons du fait du mode d'échantillonage et de la faible quantité de muscle prélevé. La fraction troponine tropomyosine doit comporter une partie non négligeable d'actine dénaturée.

L'activité catheptatique $\mathrm{D}$, mesurée in vitro après éclatement des lysosomes, ne reflète pas forcément l'intensité du catabolisme protéique in vivo.

c) Méthodes de calcul de la constante de synthèse $K$ s.

La détermination des constantes de biosynthèse et de la vie moyenne des protéines sont, par principe, entâchées d'une certaine erreur qui provient d'une part de la réutilisation du précurseur et d'autre part de l'assimilation de la RAS de la lysine libre totale du tissu à celle de la lysine fixée à l'ARN de transfert. L'hétérogénéité du pool dans lequel la RAS du précurseur est mesurée constitue la principale critique de ces méthodes de mesure de la synthèse protéique.

L'état dynamique de ce pool doit être également pris en considération. Le passage de la lysine ${ }^{-14} \mathrm{C}$ libre plasmatique dans le pool intracellulaire du muscle est lent. De plus, le marqueur arrive dans un pool très important de lysine non marquée. Ainsi la RAS de la lysine- ${ }^{14} \mathrm{C}$ libre dans le muscle croit lentement et n'atteint un maximum, peu prononcé, qu'entre 30 et $60 \mathrm{mn}$ après l'injection. Les variations de la RAS de la lysine-14 $\mathrm{C}$ du muscle intégre donc, outre l'utilisation du précurseur pour la synthèse protéique, un certain nombre de phénomènes qui peuvent être responsables de la matvaise relation existant entre la RAS de la lysine libre du muscle et la radioactivité incorporée dans les protéines musculaires. Il se peut également, en accord avec l'hypothèse de HIDER et al. (I969) que le pool intracellulaire ne soit pas le pool précurseur des protéines, ce pool jouant plutôt le rôle d'un réservoir de stockage des acides aminés. Selon ces auteurs, les acides aminés libres extracellulaires sont utilisés préférentiellement pour la synthèse protéique. C'est pourquoi, nous avons utilisé la RAS de la lysine- ${ }^{14} \mathrm{C}$ libre du plasma comme RAS du précurseur. Dans ce cas, la relation $\mathrm{A} / t=\mathrm{K} s \gamma(t)$ devient très significative. 
La méthode de calcul que nous avons utilisée pour le muscle, en faisant appel à des éléments de calcul statistique, permet d'estimer la précision de la constante $\mathrm{K} s$ en intégrant toutes les causes d'erreur. $\mathrm{L}_{\mathrm{L}}$ constante $\mathrm{K}_{\mathrm{E}+\mathrm{D}}$ ne peut être appréciée avec une bonne précision par cette méthode, sur la période étudiée après l'injection du précurseur, étant donné la faible importance du terme $\mathrm{K}_{\mathbf{E}+\mathrm{D}} \mathrm{N}$ devant le terme Ks $r(t)$.

Nous avons considéré que toutes les fractions protéiques du muscle sont synthétisées à partir du même pool d'acides aminés libres.

Dans le foie et l'appareil digestif, la détermination précise de la valeur de l'anabolisme réel, $\mathrm{K} s$, n'est pas possible dans le cadre de notre étude. En effet, le calcul du $\mathrm{K} s$ doit être fait avant que le maximum d'incorporation de l'acide aminé marqué dans les protéines ne soit atteint, à l'aide de 2 points expérimentaux choisis entre $o$ et $20 \mathrm{mn}$ après l'injection et nous n'avons expérimenté qu'au temps $\mathrm{I}_{5} \mathrm{mn}$. De ce fait, les résultats déterminés pour les groupes nuit sont vraisemblablement surestimés par suite d'une valeur trop faible de la RAS au temps $7,5 \mathrm{mn}$.

\section{2. - Synthèses protéiques dans les différents tissus}

a) Vitesse de synthèse et temps de renouvellement des protéines des différents tissus.

Dans le foie et l'appareil digestif, les valeurs du Ks sont en bon accord avec les résultats de VANDERMEERS et al. (1967):7,3 mg de protéines synthétisées par gramme de foie et par heure et 5, I mg dans le pancréas. MIILWARD et GARLICK (I972), après infusion de tyrosine $-{ }^{14} \mathrm{C}$, trouvent une synthèse horaire de $4 \mathrm{mg}$ environ par gramme de foie et $5 \mathrm{mg}$ par gramme de tissu intestinal. PETERS et PETERS (I972) ont mesuré, par incorporation de leucine- ${ }^{14} \mathrm{C}$, la quantité de protéines synthétisées dans le foie de rat de $200 \mathrm{~g}$. La valeur de Ks mesurée à $22 \mathrm{~h}$, soit $4 \mathrm{~h}$ après le début de la phase sombre, est voisine de celle que nous avons déterminée dans les mêmes conditions : l'écart est de $r_{7}$ p. Ioo. De même, les temps de renouvellement sont du même ordre de grandeur que ceux cités par VANDERMEERs et al. (I967) $24 \mathrm{~h}$ pour le foie et $34 \mathrm{~h}$ pour le pancréas.

La valeur de la constante de synthèse des protéines totales du muscle obtenue est en bon accord avec la valeur de $0,75 \mathrm{mg} / \mathrm{g} /$ heure déterminée par MILI,WARD et GARLICK (I972) par infusion de tyrosine- ${ }^{14} \mathrm{C}$.

Les valeurs au temps de renouvellement des protéines totales du muscle sont du même ordre de grandeur que celles citées par les auteurs récemment : 5,7 $\mathrm{g}$ (WATERLow et Stephen, r968) ; io j (Garlick, I969) ; 7,5 j (ARnal et al., r97I) ; $8,6 \mathrm{j}$ (MILLWARD, I970).

Les protéines sarcoplasmiques et myofibrillaires ont des temps de renouvellement voisins, ce qui est en accord avec Millward et Garlick (I972). Milliward (I970) cite un temps de 7,2 j pour les protéines myofibrillaires. Pour la myosine et l'ensemble troponine tropomyosine, nos valeurs sont en bon accord avec la classification de Funabiki et Cassens (I97I) établie par double marquage. Le temps de renouvellement de la myosine, est du même ordre de grandeur que celui cité par Krmata et MORKIN (I97I) (Io,6 j). 
b) Infuence de l'heure d'injection du précurseur sur la quantité de protéines synthétisées par les différents tissus.

Quel que soit le lot considéré, la quantité de protéines synthétisée dans le foie et l'appareil digestif est plus importante chez les groupes nuit que chez les groupes jour, surtout dans le cas du lot ad libitum. Or, il est bien établi que le métabolisme protéique du foie est en étroite relation avec l'apport d'acides aminés alimentaires. WANNEMACHER et al. (I97I) ont montré qu'il y avait une bonne corrélation entre 1'apport d'acides aminés au foie et leur incorporation dans les protéines hépatiques. D'après nos résultats, il semble en être de même pour l'appareil digestif.

Dans le cas du lot ad libitum, la synthèse des protéines accrue la nuit dans ces organes peut donc être mise en relation avec l'apport d'acides aminés alimentaires, lié au rythme de consommation. Cet apport se manifeste également par une diminution de la RAS de la lysine libre la nuit, due en partie à la dilution du marqueur par un apport important de lysine alimentaire, et par une augmentation de la teneur en lysine libre du foie. Dans le cas du lot recevant l'alimentation contrôlée, les mêmes phénomènes sont observés, par suite de la modification, au cours du nycthémère, de la vitesse de la vidange stomacale.

I a quantité totale de protéines musculaires synthétisées est plus élevée le jour que la nuit dans le lot ad libitum, ce qui rejoint les résultats de REBOLLERO et GAGLIARDINo (I97I) chez la souris. Par contre, dans le lot repas, la synthèse varie peu au cours de la journée, peut-être par suite d'une surestimation de la synthèse des protéines sarcoplasmiques durant la phase sombre.

La synthèse des protéines sarcoplasmiques est plus importante la nuit que le jour, surtout dans le lot repas, alors que les protéines myofibrillaires et les protéines du stroma sont synthétisées préférentiellement le jour. Les différences de vitesse de synthèse des protéines sont déjà visibles au niveau de la quantité de radioactivité incorporée dans les protéines. En effet, le rapport des pentes des droites d'incorporation $(\mathrm{N}=a \log t-b)$ des protéines sarcoplasmiques et myofibrillaires est inférieur à I le jour et supérieur à I la nuit.

c) Influence du rythme alimentaire.

Le rythme de consommation alimentaire influence la quantité de protéines synthétisées. En effet, l'alimentation contrôlée entraîne une diminution de 50 p. Ioo des synthèses protéiques du foie et de l'appareil digestif étant donné que la RAS de la lysine libre est plus élevée et la radioactivité incorporée dans les protéines plus faible.

Cette diminution des synthèses au niveau du foie et de l'appareil digestif entraîne une augmentation de la quantité d'acides aminés disponibles pour d'autres synthèses dans l'organisme et en particulier au niveau du muscle. En fait, l'alimentation contrôlée n'entraîne pas d'augmentation des synthèses protéiques globales du muscle. Cependant, elle semble améliorer la synthèse de certaines fractions, en particulier les protéines sarcoplasmiques la nuit.

\section{3. - Catabolisme protéique : activité catheptasique $D$ totale}

L'activité catheptasique $\mathrm{D}$ du muscle et surtout du foie est plus importante chez le lot ad libitum groupe jour que chez les 3 autres groupes. Le catabolisme pro- 
téique semble plus intense lorsque l'apport alimentaire est plus élevé. FILkINs (I970) a montré que l'activité de certaines enzymes lysosomales augmente au cours du jeûne. Cet auteur souligne que l'intervention de ces enzymes, durant les périodes de jeûne relatif comprises entre les repas, est possible au cours de la journée. D'autre part, il est bien connu, que lorsque l'apport alimentaire augmente, l'organisme stocke des acides aminés sous forme de protéines labiles dans le foie essentiellement. Ces protéines peuvent être rapidement dégradées lorsque le taux protéique du régime diminue ou pendant les périodes situées entre les repas. Elles semblent constituées d'un certain nombre d'enzymes hépatiques (Munro, I964). Durant les phases d'absorption il doit y avoir accumulation de protéines labiles dans le foie, ces composés sont ensuite catabolisés entre les repas de façon à assurer 1'homéostasie et les besoins de synthèse de l'organisme.

L'activité catheptatique $\mathrm{D}$ des tissus des animaux soumis aux repas est moins élevée que celle des tissus du lot ad libitum. L'alimentation contrôlée entraîne une limitation du catabolisme protéique dans le foie et surtout dans le muscle. Ceci est en faveur d'un anabolisme apparent plus élevé lorsque les animaux sont nourris au rythme de 6 repas par jour et explique la rétention azotée, augmentée de 5 p. Ioo, décrite par Bouvier et al. (I973).

\section{4. - Catabolisme de la L-lysine-14C. \\ Quantité de lysine oxydée par heure}

Par un calcul dont nous ne rappellerons pas les détails ici (OBLED et al., I973), nous avons montré que la quantité de lysine oxydée par heure est plus élevée pendant la phase sombre que pendant la phase claire : I,8 $\mathrm{mg}$ contre $0,7 \mathrm{mg}$ pour le lot ad libitum et I $\mathrm{mg}$ contre $0,5 \mathrm{mg}$ pour le lot repas respectivement. De plus, le catabolisme de la lysine est plus faible lorsque l'alimentation est régulièrement distribuée au cours du nycthémère.

La dégradation de certains acides aminés est en relation avec l'alimentation. En effet, l'induction des enzymes intervenant dans leur catabolisme est provoquée par les acides aminés alimentaires (HARPER, I965; Solimax et HarPER, I97r; YAMASHITA et ASHIDA, I97I; BROOKES et al, r972). Une telle relation est effectivement observée au cours de la journée, les synthèses protéiques étant accrues dans le foie et l'appareil digestif. L'activité de la tyrosine transaminase et d'autres enzymes hépatiques sont plus élevées durant la phase sombre (Wurtman, I970). Cette étude nous permet d'énoncer, en accord avec Munro (I969) que l'activité anabolisante du foie et de l'appareil digestif en réponse à un apport plus important d'acides aminés alimentaires au cours de la journée se manifeste partiellement par la synthèse d'enzymes et en particulier d'enzymes du catabolisme des acides aminés.

\section{5. - Conclusion}

La modification du rythme alimentaire a perturbé le métabolisme protéique des animaux. A la lumière de nos résultats, nous pouvons schématiser ces changements de la façon suivante.

Lorsque les rats sont nourris ad libitum, la nuit les animaux sont hyperphagiques et consomment 50 à $80 \mathrm{p}$. Ioo d'énergie en plus de leurs besoins (LE MAGNEN, I973). 
Toutes les synthèses sont accrues dans le foie et 1'appareil digestif et la lysine en excès est oxydée. Le jour, le rat consomme 50 p. Ioo d'énergie en moins de ces besoins. I1 oxyde les acides gras mobilisés à partir des réserves faites la nuit précédente (LE Magnen, I973). L'animal dégrade moins les acides aminés dont une partie provient du catabolisme des protéines du foie et du muscle.

Lorsque l'alimentation est distribuée de façon régulière au cours du nycthémère, l'animal a toujours des nutriments à sa disposition, sans excès ou défaut important par rapport à ses besoins. Il en résulte, au niveau du foie et de l'appareil digestif, une diminution de la synthèse des protéines et en particulier des enzymes nécessaires à la transformation de la masse d'acides aminés alimentaires arrivant dans ces organes au cours de la nuit dans l'alimentation ad libitum. De ce fait, la quantité d'acides aminés dégradés diminue. La période de jeûne relatif de la phase claire est supprimée et le catabolisme des protéines, surtout musculaires, devient moins important. Il en résulte une meilleure utilisation des acides aminés.

De plus, il semble que 1'animal, malgré une distribution régulière des nutriments au cours du nycthémère, conserve un rythme propre, par suite de l'influence d'un " synchroniseur " endogène ou exogène plus fort que le rythme alimentaire, 1'alternance nuit-jour par exemple.

Contrairement au foie et à l'appareil digestif, dont le métabolisme protéique est en étroite relation avec 1'apport cyclique des nutriments, la synthèse protéique au niveau du muscle est indépendante du rythme alimentaire. Cette indépendance peu apparente au niveau des protéines totales, se manifeste par l'augmentation de la synthèse des protéines myofibrillaires au cours de la phase claire. Par contre, les protéines sarcoplasmiques, par suite de l'influence de certaines fractions à renouvellement très rapide, ont un rythme identique à celui des protéines du foie et de 1'appareil digestif.

Reģu pour publication en décembre 1974.

\section{REMERCIEMENTS}

Nous remercions vivement $J$. Prugnaud pour les analyses radiochromatographiques de lysine-14C et J. Grizard pour son aide dans l'interprétation statistique de nos résultats.

\section{SUMMARY}

FEEDING SCHEDULE AND IN VIVO PROTEIN SYNTHESIS

IN VARIOUS TISSUES OF THE, GROWING RAT

Growing rats $(6.7 \mathrm{~g} /$ day) were fed either ad libitum or in 6 equally distrituted meals every 4 hours from to $\mathrm{h} 30$ each morning in a room illuminated between $07 \mathrm{~h}$ oo and $19 \mathrm{~h}$ oo. The rats received Io $\mu \mathrm{Ci}$ of ${ }^{14} \mathrm{C}$-L-lysine by intraperitoneal injection at either ${ }^{5} \mathrm{~h}$ oo or $23 \mathrm{~h}$ oo. Protein synthesis in the liver, digestive apparatus (minus liver) and different protein fractions of the muscle was estimated from the radioactivity incorporated into the proteins, taking into account the radioactivity of the precursor. Protein catabolism in the liver and muscle was estimated from the total cathepsin (D) activity of these tissues. The oxidative catabolism of the lysine was determined by measuring the evolution of the specific radioactivity of the ${ }^{14} \mathrm{CO}_{2}$. 
Irrespective of the feeding schedule, the level of protein synthesis in the liver and digestive apparatus during the night was higher than that observed during the day. Protein synthesis in muscle appears to be independent of the feeding schedule, whereas total protein as well as myofibrillar protein were synthesized in greater quantities during the periods of illumination. The synthesis of sarcoplasmic protein followed a rhythm parallel to that of the proteins of the liver and digestive apparatus.

Controlled feeding resulted in a reduction of the protein synthesis in the liver and digestive apparatus and also in a reduction in the quantity of lysine oxidized. True protein synthesis in the muscle was, howewer, not significantly influenced by the feeding schedule. On the other hand, synthesis of sarcoplasmic proteins increased and protein catabolism decreased in the liver, and particularly in the muscle, in rats receiving the scheduled meals.

The results correlate the best nitrogen retention with scheduled meals.

\section{RÉFÉRENCES BIBLIOGRAPHIQUES}

Arnal M., fauconneau G., Pech R., ig7i. Étude de la synthèse protéique in vivo : mesure de l'activité anabolisante de divers tissus du Rat en croissance à l'aide de la L-lysine-11C (U). Ann. Biol. anim. Bioch. Biophys., 11, 245-264.

Bouvier J. C., Perez M., Vermorel M., Aurousseau B., ig73. In : Régulation de l'équilibre énergétique chez l'Homme. Ed. ApFelbaum M., p. 3II-3I7, Masson et Co, Paris.

Brookes I, M., OWEns F. N., Garrigus U. S., 1972. Influence of amino acid oxidation by the rat. J. Nutr., 102, 27-36.

Cons C., JosePH D., I959. Changes in body composition attendant on forn-feeding. Ann.J.Physiol., 196, 965 .

FABRY P., 1967. Metabolic consequences of the pattern of food intake. In Handbook of physiology, alimentary canal. Ann. Physiol. Soc., 31.

Filkins J. P., I970. Lysosomes and hepatic regression during fasting. Am. J. Physiol., 219, $923-927$.

Fishman B., Wutman R. J., Munro H. N., 1969. Daily rhythms in hepatic polysome profiles and tyrosine transaminase activity : role of dietary protein. Proc. Nat. Acad. Sci., 64, 677-68z.

FRIEND D. W., I 967 . Weight gains, nitrogen metabolism and body composition of rats fed one or five meal daily. Can. J. Physiol. Pharmacol., 45, 367 .

Fuller R. W., SNoddy H. D., I 967 . Feeding schedule alteration of daily rhythm in tyrosine cetoglutarate transaminase of rat liver. Science, 159, 738 .

Funabiki R., Cassens R. G., I97r. Turnover of the muscle protcins. J. anim. Sci., 33, II43.

Ciardick P. J., r 969 . Turnover rate of muscle protein measured by constant intravenous infusion of ${ }^{14} \mathrm{C}$-glycine. Nature, 223, 6r-62.

Girand-Globa A., Bourdel G., 1973. Physiological regulation of the circadien rythm in hepatic tyrosine transaminase. Schedule of protein ingestion as a determinant factor. J. Nutr.. 103, 251-256.

HARPER A. E., I965. Effect of variations in protein intake on enzymes of amino acid metabolism. Can. J. Biochem., 43, I589-1603.

Hellander E., r957. On quantitative muscle protein determination. Acta Physiol. Scand., 41, 3-99.

Hider R. C., Fern E. B., London D. R., 1969. Relationship between intracellular amino acids and protein synthesis in the extensor digitorum longus muscle of rats, Biochem. J., 114, I7I-178.

Kimata S., Morkin E., I97I. Comparison of myosin synthesis in heart and red and white skeletal muscles. Amer. J. Physiol., 221, I706-1713.

Le bouton A. V., Handler D. S., 1970. Diurnal incorporation of ${ }^{3} \mathrm{H}$-leucine into liver protein. Febs. Letter, 10, 78-80.

Le MAGnen J., 1973. La neurophysiologie de la faim. La Recherche, 4, 445-455.

Lewis R. E., Kunz A. L., Bell R. E., 1966. Error of intraperitoneal injections in rats. Lab. anim. care, 16, 505-509.

Millward D. J., I970. Protein turnover in skeletal muscle. I. The measurement of rates of synthesis and catabolism of skeletal protein using ${ }^{14} \mathrm{C}-\mathrm{Na}_{2} \mathrm{CO}_{3}$ to label protein. Clin. Sci., 39, 577-59o.

Millward D. J., Garlick P. J., I972. The pattern of protein turnover in the whole animal and the effect of dietary variations. Proc. Nutr. Soc., 31, 257-263.

Moore S., Spackman D. H., Stern H. H., 1958. Chromatography of amino acids on sulfonated polystyrene resins. An improved system. Analyt. Chem., 30, I $18_{5}$-I I9o.

Munro H. N., 1964. In : Mammalian protein metabolism. Ed. Munro H. N. Vol. I, p. 382, Academic Press, New York and London.

Munro H. N., 1969. Adaptation of mammalian protein metabolism to amino acid supply. Proc. Nutr. Soc., 28, $215-225$. 
Orled C., Arnal M., Fauconneau G., 1972. Rythme circadien de la synthèse protéique dans quelques tissus du rat en croissance : influence du comportement alimentaire. C. R. Soc. Biol., 166, 885-89I.

Obled C., Arnal M., Fauconneau G., 1973. Circadian rhythm of the oxidative catabolism of lysine in growing rats. Influence of feeding schedule. Nutr. Rep. Int., 8, 81-86.

Овцед C., I973. Étude de la synthèse protéique in vivo dans différents tissus du rat en croissance: infuence du comportement alimentaire. Thèse, Clermont-Ferrand.

Peters T., Peters J. C., I972. The biosynthesis of serum albumin. VI-Intracellular transport of albumin and rates of albumin and liver protein synthesis in vivo under various physiological conditions. J. Biol. Chem., 347, $3858-3863$.

Potter V. R., Gebert R. A., Pitot H. C., Peraino C., Lamar C., Lesjer S., Morris H. P., I966. Systematic oscillations in metabolic activity in rat liver and in hepatomas. I. Norris Hepatoma $\mathrm{n}^{\circ} 7793$. Cancer Res., 26, $1547-1560$.

Rebodello O. R., Gagliardino J. J., I97I. Circadian variations of the protein metabolism in muscle J. Interdisc. Cycle Res., 2. гот-ro8.

Snedecor G. W., Cochran W. G., 1957. Methodes statistiques, Association de coordination technique agricole. Paris.

Soliman A. G., Harper A. E., I97I. Effect of protein content of diet on lysine oxidation by the rat. Biochem. Biophys. Acta, 244, 146-154.

Symmons R. A., Maguire E. J., Rogers Q. R., I972. Effect of dietary protein and feeding schedule on hepatic polysome parterns in the rat. J. Nutr., 102, 639-646.

Szent Gyorgi A., Kaminer B., 1963. Metin and metactomyosin. Proc. Nat. Acad. Sci., L.S. A., 50, I033.

VALiN C., I967. Isolement d'une fraction protéique à activité protéolytique du muscle de bovin. $A n n$. Biol. anim. Biochem. Biophys., 7, 475-483.

VANDERMeErs A., VAndermeers-Piret M. C. Christophe J., I967. Synthèse protéique in vivo dans le pancréas et le foie de rat normal, carencé en lysine et en thréonine ou récupérant de cette carence. Bull. Soc. Chim. Biol., 49, 759-778.

Vandermeers A., Khayat M. H., Rathe J., Christophe J., ig68. Vies moyennes de cinq hydrolases dans le pancréas du rat normal ou en malnutrition protidique. Biochem. Biophys. Acta, 158, $448-455$.

Wannemacher R. W., Wannemacher C. F., Yatvin M. B., I97I. Amino acid regulation of synthesis of ribonucleic acid and protein in the liver of rats. Biochem. J., 124, 385-392.

Waterlow J. C. Stephen J. M. L., I968. The effect of low protein diets on the turnover rates of serum, liver and muscle proteins in the rat, measured by continous infusion of $\mathrm{L}^{-14} \mathrm{C}-\mathrm{lysine}$. Clin. Sci., 35, 2887-305.

Wurtman R. J., I97o. In : Mammalian protein metabolism. Ed. Munro H. N., vol, 4, p. 445, Academic Press, New York and London.

Yamashita K., Ashida K., I97i. Effect of excessive levels of lysine and threonine on the metabolism of these amino acids in rats. J. Nutr., 101, I607-I6I4. 